\title{
Use of a Profile Board in Sand Shinnery Oak Communities
}

\author{
FRED S. GUTHERY, TED B. DOERR, AND MAPLE A. TAYLOR
}

\begin{abstract}
A profile board adapted to sand shinnery oak communities gave highly accurate structural profiles of the vegetation. Using actual estimates of percentage screening of strata by foliage was more accurate than using percentage screening classes. The procedures used to adapt the profile board to sand shinnery oak communities can be used in other plant communities.
\end{abstract}

Boards or poles painted with strata of alternating colors are used to index the structural density of vegetation by recording visual obstruction of the strata by foliage. Such devices have broad application in analysis of wildlife habitat. With various designs, they have, for example, been used to (1) determine the height of vegetation on prairie grouse leks (Kobriger 1965), (2) index density of vegetation in greater prairie chicken (Tympanuchus cupido) habitats (Robel et al. 1970), (3) identify variation in the vegetative structure of habitats used by rodents (M'Closkey and Fieldwick 1975), and (4) determine the effects of herbicide treatments on screening cover of white-tailed deer (Odocoileus virginianus) habitats (Tanner et al. 1978). Nudds (1977) developed a profile board for southeastern forests which can be used to quantify structural density by height classes. The resulting data allow statistical comparisons of the vertical structural profiles of different plant communities.

The need to quantify the effects of a herbicide (tebuthiuron) on the structure of lesser prairie chicken (T. pallidicinctus) habitat prompted this study. Objectives were to (1) adapt Nudds' (1977) profile board to plant communities dominated by sand shinnery oak (Quercus havardii), (2) determine the accuracy of this technique, and (3) determine sample size required to obtain valid vegetation profiles.

\section{Materials and Methods}

Ficld data were collected during July and August 1978 in Yoakum and Cochran counties and July 1979 in King County, Texas. Pettit (1979) described the shinnery oak communities occupying these areas.

We tested four profile board designs for suitability in analyzing habitats dominated by sand shinnery oak. Boards $(1.2 \mathrm{~m}$ tall) of two widths $(6.80$ and $8.82 \mathrm{~cm})$ were painted in alternating black and white strata $1.0 \mathrm{dm}$ tall on one side and $1.5 \mathrm{dm}$ tall on the reverse side. Strata were numbered consecutively, bottom to top, with numbers $3 \mathrm{~cm}$ tall.

The optimum distance to "read" profile boards occurs where perceived variation in foliage screening of strata is greatest (Nudds 1977). To determine this distance, we recorded density scores, by strata, at $2,4,6,8$, and $10 \mathrm{~m}$ from the board. Nudds'density score is a digit value corresponding to the proportion of a stratum screened by vegetation ( 1 corresponds to $0-20 \%, 2$ corresponds to $21-40 \%$, etc.). Boards were placed at 20 randomly selected points in each of two plots and read from a kneeling position. One plot was untreated; the other had been treated with $0.5 \mathrm{~kg} / \mathrm{ha}$ of tebuthiuron in May 1978. The treated plot approximated winter conditions because most of the sand shinnery oak was dead and had shed leaves. The sum of density score variances for six strata was determined by unique combinations of four board designs, five

Authors are, respectively, assistant professor, research associate, and research assistant, Department of Range and Wildlife Management, Texas Tech University Lubbock 79409

This is College of Agricultural Sciences, Texas Tech University, Publication No. T-9-202.

The Noxious Brush and Weed Control Program, Department of Range and Wild life Management, Texas Tech University, provided financial support for this study. Manuscript received August 11, 1979. distances, and two plots. This sum was hypothesized to be a negative quadratic function of distance because variation in screening should be low near to and far from the board. Sums of density score variances from the two plots were lumped for each board design to compute, using least squares, quadratic functions relating sum of strata variances to distance. The distance at which maximum variation occurred was determined by finding the quadratic function's derivative and evaluating it at 0 .

Preliminary work indicated that Nudds' (1977) density scores were inappropriate for plant communities dominated by sand shinnery oak. In our study area, height of vegetation was fairly uniform at 5-6 dm with longer stems occasionally rising to 10-12 $\mathrm{dm}$. When a single stem intersected a stratum, assigning a density score of $1(0-20 \%)$ resulted in gross overestimation of percentage screening. Similarly, assigning a value of $4(81-100 \%)$ to the lower strata, which invariably had $100 \%$ screening, resulted in underestimation. Therefore, we used density scores of $0(0 \%), 1>0-5 \%), 2$ (6-20\%), $3(21-40 \%), 4(41-60 \%), 5(61-80 \%), 6(81-95 \%)$, and 7 $(>95 \%)$. Following Daubenmire's (1959) logic, we used the midpoints of classes 1 through 7 to compute mean density scores.

To test for accuracy, we enlarged 10 black-and-white photographs of the profile board placed in vegetation dominated by sand shinnery oak. These $40.6-\times 50.8-\mathrm{cm}$ enlargements were read by ten individuals who assigned our density score classes and who estimated the actual percentage screening of eight strata per photograph. The estimates of actual percentage screening were later used to assign Nudds'(1977) density scores. The true percentage screening of strata was determined by overlaying individual strata on the photographs with stipplings $\left(72 \mathrm{dots} / \mathrm{cm}^{2}\right)$ and determining the percentage of dots that intersected vegetation. This technique probably was accurate because each stratum contained over 1,000 dots. True percentage screening subsequently was correlated with the midpoints of the percentage ranges for Nudds' (1977) density scores and our density scores and with the estimates of actual percentage screening.

We assumed that when sample size was adequate, additional observations would have minor effect on mean density scores. We determined required sample size by randomly sampling 60 points in four vegetation types dominated by sand shinnery oak and calculating mean density scores, by strata, at increments of ten observations.

\section{Results and Discussion}

The profile board with width of $6.8 \mathrm{~cm}$ and strata of 1.0 dm (Fig. 1) proved most acceptable of the four tested. This design had the only significant $(P<0.05)$ negative quadratic model relating sum of strata variances to distance when data from the two plots were combined. Maximum estimated variation in density scores occurred at $7.1 \mathrm{~m}$ from the board, which can be rounded to $7 \mathrm{~m}$ for field application.

Correlation analyses revealed that all observers accurately estimated the percentage visual obstruction of strata on the profile board. Whether they used Nudds' (1977) classes, our classes, or no classes, the correlations between true and estimated percentage screening were highly significant $\left(0.8 \leq r^{2} \leq 0.98, \mathrm{n}=80\right.$ per observer, $\left.\mathrm{P}<0.01\right)$. However, Nudds' (1977) classes had lower $r^{2}$ values than our new classes in ten of ten cases, and our classes had lower $r^{2}$ values than unclassed estimates in nine of ten cases. The average absolute value of the difference between true mean percentage screening and estimated mean percentage screening was 


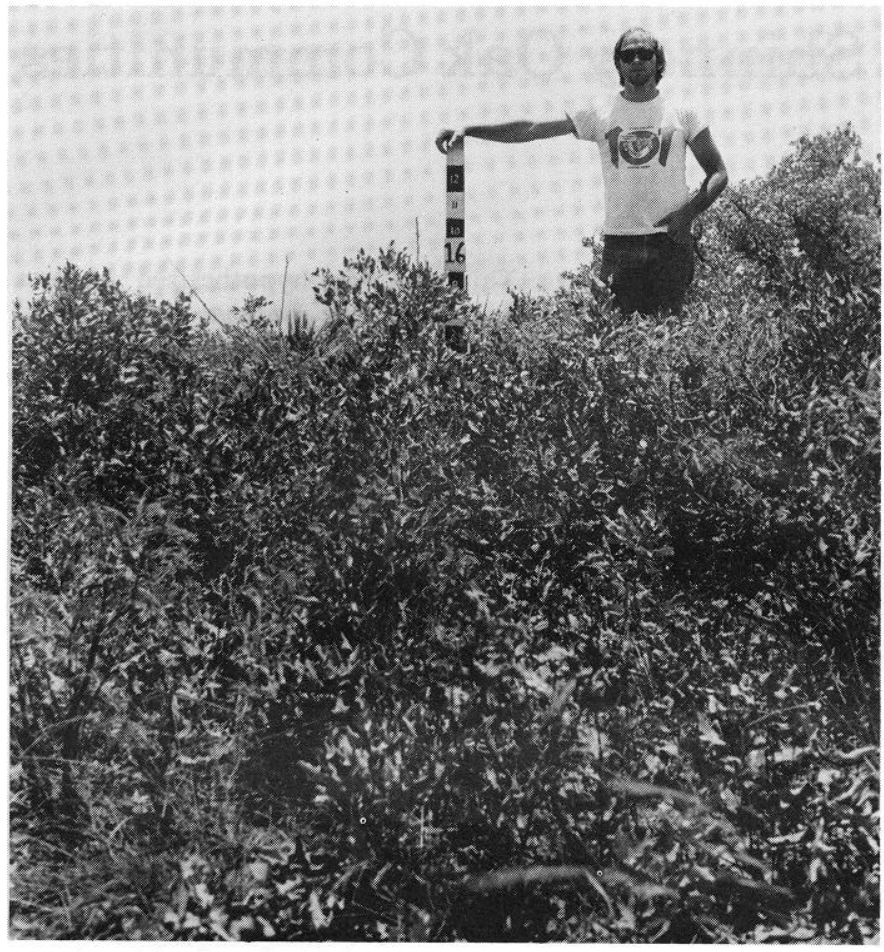

Fig. 1. A vegetation profile board adapted to plant communities dominated by sand shinnery oak.

highest with Nudds' (1977) classes, intermediate with our classes, and lowest with unclassed estimates. These results strongly suggest that percentage screening classes decrease the accuracy of profile board readings and, therefore, actual estimates of percentage screening should be used.

Observers tended to underestimate percentage screening for all strata except the two lowest and the highest, but in only 1 of 80 cases did the estimated mean percentage screening (actual estimates used) fall outside the $95 \%$ confidence limits of the true mean percentage (Fig. 2). Estimates were without error on the lowest stratum because vegetation screening was $100 \%$ on all photographs.

A sample size of 50 was acceptable in the four vegetation types analyzed. The mean absolute value of the difference between mean density scores, by strata, was less than $1.1 \%$ in each vegetation type when sample size increased from 50 to 60 points. With a sample size of 50 , the standard error ranged between 5 and $25 \%$ of the mean percentage screening in central strata. Variances were highest in these strata (Fig. 2).

Although sand shinnery oak communities occur only in Oklahoma, New Mexico, and Texas, the profile board we adapted may well be useful in any plant community dominated by low shrubs. If not, the procedures used to determine optimum distance from which to read the board, accuracy, and required sample size could be used in any plant community.

The high accuracy of profile board readings was gratifying, because this is an inexpensive, rapid method of measuring the structural profile of vegetation. In our work, two men (one to hold the board and one to record density scores)

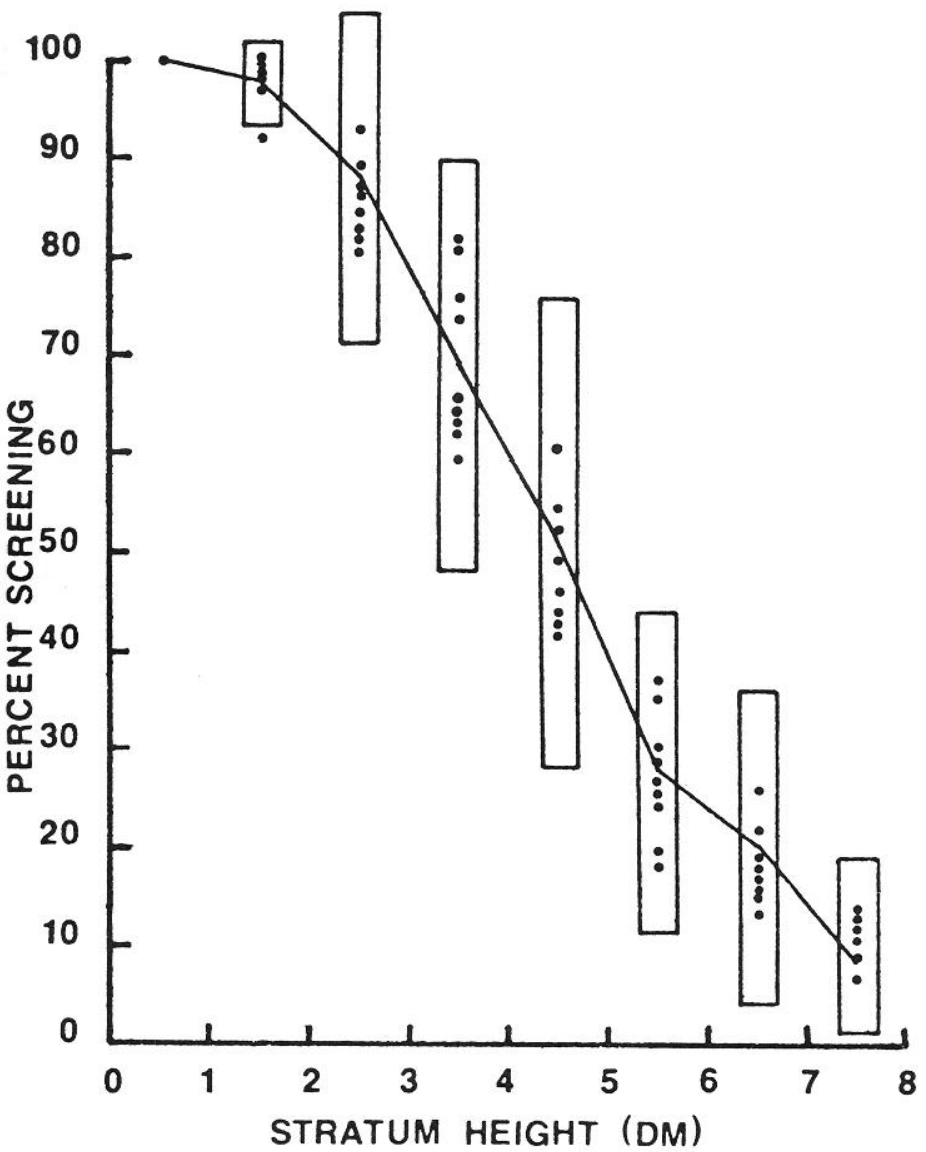

Fig. 2. Comparison of mean percentage screening of profile board strata as estimated by ten individuals (dots) with true mean percentage screening (line) as determined from measurements on photographs of the profile board placed in sand shinnery oak vegetation. Rectangles represent $95 \%$ confidence limits on the measured screening values. Fewer than ten dots occur when duplicate estimates existed.

surveyed 60 points in 40 minutes or less. One observer can use the board if it is affixed with a hinged stand (Nudds 1977).

\section{Literature Cited}

Daubenmire, R. 1959. A canopy-coverage method of vegetation analysis. Northwest Sci. 33:43-63.

Kobriger, G.D. 1965. Status, movements, habitats, and foods of prairie grouse on a sandhills refuge. J. Wildl. Manage. 29:788-800.

M'Closkey, R.T., and B. Field wick. 1975. Ecological separation of sympatric rodents. J. Mammal. 56:119-129.

Nudds, T.D. 1977. Quantifying the vegetative structure of wildlife cover. Wildl. Soc. Bull. 5:113-117.

Pettit, R.D. 1979. Effects if picloram and tebuthiuron pellets on sand shinnery oak communities. J. Range Manage. 32:196-200.

Robel, R.J., J.N. Briggs, J.J. Cebula, N.J. Silvy, C.E. Viers, and P.G. Watt. 1970. Greater prairie chicken ranges, movements, and habitat usage in Kansas. J. Wildl. Manage. 34:286-306.

Tanner, G.W., J.M. Inglis, and L.H. Blankenship. 1978. Acute impact of herbicide strip treatment on mixed-brush white-tailed deer habitat on the northern Rio Grande Plain. J. Range Manage. 31:386-391. 